\title{
Infertility in Men with Varicocele: The Role of Age, Smoking and Alcohol Intake
}

\author{
Luca Coppeta ${ }^{1}$, Anna Neri $^{2}$, Maria Nicotra ${ }^{3}$, Vincenzo Gentile ${ }^{3}$, Claudio Spina ${ }^{4}$, \\ Adalgisa Pietropolli5 ${ }^{5}$ Fulvia Gloria-Bottini ${ }^{*}$ (1) \\ ${ }^{1}$ Polyclinic Foundation, University of Tor Vergata, Rome, Italy \\ ${ }^{2}$ Department of Biomedicine and Prevention, School of Medicine, University Tor Vergata, Rome, Italy \\ ${ }^{3}$ Department of Gynaecologic, Obstetric and Urologic Sciences, University of Rome La Sapienza, Rome, Italy \\ ${ }^{4}$ Department of System Medicine, University of Tor Vergata, Rome, Italy \\ ${ }^{5}$ Department of Surgery, University of Tor Vergata, Rome, Italy \\ Email: `gloria@med.uniroma2.it
}

How to cite this paper: Coppeta, L., Neri, A., Nicotra, M., Gentile, V., Spina, C., Pietropolli, A. and Gloria-Bottini, F. (2020) Infertility in Men with Varicocele: The Role of Age, Smoking and Alcohol Intake. Health, 12, 231-239.

https://doi.org/10.4236/health.2020.123019

Received: October 7, 2019

Accepted: March 8, 2020

Published: March 11, 2020

Copyright (c) 2020 by author(s) and Scientific Research Publishing Inc. This work is licensed under the Creative Commons Attribution-NonCommercial International License (CC BY-NC 4.0).

http://creativecommons.org/licenses/by-nc/4.0/

\begin{abstract}
Previous studies have focused on the damaging effects of smoking and alcohol on sperm parameters; however, some of these studies have failed to find a significant correlation between these variables. Herein we have investigated the relationship of infertility with smoking and/or alcohol consumption in one hundred and thirty-six men with varicocele, admitted consecutively to the Outpatients Department of Infertility at the University of Rome La Sapienza (Italy) between 2005-2007. The sample size was small because we have selected couples with both marital infertility lasting for more than two years and the male partner with varicocele. Statistical analyses were carried out using the software of Statistical Package for the Social Sciences (SPSS). We showed a highly significant association of infertility with alcohol consumption. As the mean value was 32 years, comparing men of age less than or equal to 32 years and men of age over 32 years, this association is present only in men of age less than or equal to 32 years. A discriminant analysis with infertility as dependent variable and age, alcohol consumption and smoking habit as independent variables has shown a significant discrimination only in men of age less than or equal to 32 years. The most important contribution to this discrimination was given by alcohol followed by age while contribution from smoking was small. Our analyses suggest that alcohol consumption contributes to infertility in men of age less than or equal to 32 years whereas smoking does not.
\end{abstract}

\section{Keywords}

Age, Alcohol Consumption, Infertility, Smoking, Varicocele 


\section{Introduction}

A large number of studies have assessed the negative effect of alcohol consumption and/or smoking on sperm parameters, but the results remain controversial. Some studies have suggested a negative association between alcohol intake and semen quality but they could not confirm that a moderate consumption impairs semen parameters [1]. By comparing infertile non-smokers to infertile smokers a significant decrease in sperm count, progressive motility, normal forms and viability among them was observed [2]. Harmful effects of combined cigarette smoking and alcohol intake on fertility and reproduction are evident. Heavy smokers and heavy drinkers have worse seminal parameters in comparison to moderate smoking/drinking and nonsmoking/abstaining [3]. Several studies have reported an association of alcohol consumption and smoking with fertility disorders [4] [5], however, a worrying phenomenon of tobacco and alcohol consumptions keeps increasing, particularly among younger subjects [4].

In a comparison of smokers with non smokers, active smoking, even if in small amount, is associated with a decreasing sperm concentration while no significant correlation is present with morphology or sperm motility [6]. The components in cigarette smoke can induce genetic and epigenetic alterations in infertile men [2] [7]. Sexual dysfunction is common in male patients with alcohol dependence [8]. The association between alcohol consumption and mortality seems to vary depending on the amount of alcohol consumed. The consumption of light or moderate quantity of alcohol might reduce mortality from cardiovascular diseases. This favorable effect is not found for cigarette smoking [9].

The association of varicocele with infertility has been widely examined although with not agreement in results. Varicocele is associated to an amendable male infertility. It is probably the cause of subfertility and can induce pathophysiological mechanisms and between these the oxidative stress has a central role. Many studies suggest that varicocelectomy influences positively semen quality and pregnancy results and about the progressive deterioration of semen parameters it seems there is a substantial difference between adults and adolescents [10] [11] [12]. In the present study we have studied couples with a history of infertility of more than two years and male partners with varicocele to deepen the role of varicocele in infertility. In this group of subjects we have assessed the relationship of infertility with smoking habit and/or alcohol intake.

\section{Subjects and Methods}

This study was carried out on 136 patients with varicocele admitted consecutively to the Outpatients Department of Infertility, a public center of infertility frequented by people of lower-middle social class, at the University of Rome La Sapienza (Italy) between 2005-2007. 59 patients were infertile men and the average age of the sample was of 32 years. All patients gave informed consent to participate in the study that was approved by the Department Council. Part of these patients has been included in previous studies [13] [14] [15] Diagnosis of vari- 
cocele was confirmed by use of the scrotal eco-colordoppler (TOSHIBA APLIO $\mathrm{XV}$ ). Analysis of spermatic liquid was performed according to the World Health Organization (WHO) criteria (1999). Seminal liquid was obtained after sexual abstinence for three to five days. All subjects had no fever, no pharmacological treatment with non-steroidal anti-inflammatory drugs, antibiotics or cortisones in the two weeks preceding the examination. The whole spermatic liquid was collected in a sterile container and delivered to the laboratory within $60 \mathrm{~min}$. Spermatic parameters were determined from the seminal liquid. Spermatic concentration is reported as millions of spermatozoa/ml. A typical spermatozoa and abnormal motility are reported in percent (\%).

A couple was classified as infertile if it is unable to conceive after one year of regular intercourse with the intent to conceive.

The intent of this study is to evaluate in these patients the relationship between smoking and alcohol intake and the effect of age, smoking and alcohol on infertility.

Chi-square test of independence, Student $t$ test, correlation analysis and discriminant analysis were carried out using the software Statistical Package for the Social Sciences-SPSS.

\section{Results}

Table 1 shows separately in fertile and infertile men the proportion of patients with/without smoking and alcohol consumption, the proportion of infertile men and the average age of the patients.

Table 2 shows the relationship between smoking and alcohol consumption with infertility. Smoking and infertility haven't association whereas alcohol consumption is significantly associated with infertility $(\mathrm{p}=0.004)$. The proportion of drinkers is very high.

Table 3 shows the relationship between smoking and alcohol and absence of both smoking and alcohol with infertility. The relationship between smokers non drinkers and between drinkers non smokers with infertility is present $(\mathrm{p}=$ $0.02)$.

Table 4 shows the correlations between smoking and infertility and between alcohol consumption and infertility. Infertility is not correlated with smoking neither in the whole sample nor in drinkers whereas it is significantly correlated with alcohol consumption in both the whole sample and in smokers $(\mathrm{p}=0.004)$.

Table 5 shows the effect of age on infertility, smoking habit and alcohol consumption. The proportion of infertile men $(\mathrm{p}<0.001)$ as well as of alcohol consumption (0.016) increases with age whereas the smokers decrease and their relation is not significant.

The average age of the patients was 32 years and Table 6 shows the correlation between infertility and smoking and alcohol consumption in relation to 32 years. Infertility is highly related to alcohol consumption only in patients with an age lower than or equal to 32 years $(\mathrm{p}=0.008)$. 
Table 1. The proportion of patients in relation to smoking, alcohol, infertility and age.

\begin{tabular}{lcc}
\hline & Proportion & Mean \\
\hline $\begin{array}{l}\text { No smoking } \\
\text { No alcohol consumption }\end{array}$ & $56.2 \%$ & \\
\hline $\begin{array}{l}\text { Yes smoking } \\
\text { No alcohol consumption }\end{array}$ & $27.3 \%$ & \\
\hline $\begin{array}{l}\text { Yes alcohol consumption } \\
\text { No smoking }\end{array}$ & $10.7 \%$ & \\
\hline $\begin{array}{l}\text { Yes smoking } \\
\text { Yes alcohol consumption }\end{array}$ & $5.8 \%$ & \\
Infertile men & $43.4 \%$ & 27.5 years \\
\hline Age & & 37.8 years \\
\hline
\end{tabular}

Table 2. The relationship of smoking and alcohol with infertility.

\begin{tabular}{|c|c|c|c|}
\hline & \multicolumn{3}{|c|}{ Smoking } \\
\hline & yes & & no \\
\hline Iinfertility & $42.2 \%$ & & $46.3 \%$ \\
\hline Total n & 45 & & 82 \\
\hline \multirow[t]{4}{*}{ Chi square test of independence } & $x^{2}$ & $\mathrm{df}$ & $\mathrm{p}$ \\
\hline & 0.199 & 1 & 0.655 \\
\hline & \multicolumn{3}{|c|}{ Alcohol Consumption } \\
\hline & yes & & no \\
\hline Infertility & $75.0 \%$ & & $40.2 \%$ \\
\hline Total n & 20 & & 102 \\
\hline \multirow[t]{2}{*}{ Chi square test of independence } & $x^{2}$ & df & $\mathrm{p}$ \\
\hline & 8.157 & 1 & 0.004 \\
\hline
\end{tabular}

Table 3. The relationship of the presence/absence of smoking and alcohol with infertility.

\begin{tabular}{|c|c|c|}
\hline & $\begin{array}{c}\text { No Smoking } \\
\text { No Alcohol Consumption }\end{array}$ & $\begin{array}{c}\text { Yes Smoking } \\
\text { Yes Alcohol Consumption }\end{array}$ \\
\hline Infertility & $39.7 \%$ & $71.4 \%$ \\
\hline Total n & 68 & 7 \\
\hline Chi square test of independence & $\begin{array}{c}x^{2} \\
2.611\end{array}$ & $\begin{array}{c}\mathrm{p} \\
0.106\end{array}$ \\
\hline & $\begin{array}{c}\text { Smoking } \\
\text { No Alcohol Consumption }\end{array}$ & $\begin{array}{c}\text { Alcohol Consumption } \\
\text { No smoking }\end{array}$ \\
\hline Infertility & $39.4 \%$ & $76.9 \%$ \\
\hline Total n & 33 & 13 \\
\hline Chi square test of independence & $\begin{array}{c}\chi^{2} \\
5.254\end{array}$ & $\begin{array}{c}\mathrm{p} \\
0.022\end{array}$ \\
\hline
\end{tabular}


Table 4. The correlation between alcohol consumption and infertility and between smoking and infertility.

\begin{tabular}{cccc}
\hline & & $\begin{array}{c}\text { Controlling for } \\
\text { alcohol consumption }\end{array}$ & $\begin{array}{c}\text { Controlling for } \\
\text { smoking }\end{array}$ \\
\hline $\begin{array}{c}\text { Smoking } \\
\text { and } \\
\text { Infertility }\end{array}$ & $\mathrm{r}=-0.003$ & $\mathrm{r}=0.030$ & \\
\hline $\begin{array}{c}\text { Alcohol Consumption } \\
\text { and }\end{array}$ & $\mathrm{p}=0.974$ & 0.259 & $\mathrm{r}=0.264$ \\
Infertility & $\mathrm{p}=0.004$ & $\mathrm{p}=0.004$ \\
\hline
\end{tabular}

Table 5. The effect of age on infertility, smoking and alcohol consumption.

\begin{tabular}{cccc}
\hline & \multicolumn{3}{c}{ AGE } \\
\cline { 2 - 4 } & $\leq 28 \mathrm{yr}$ & $>28 \leq 32 \mathrm{yr}$ & $>32 \mathrm{yr}$ \\
\hline Infertility & $2.5 \%$ & $20.8 \%$ & $81.0 \%$ \\
Chi square test of independence & & $\mathrm{p}<0.001$ & \\
\hline Smoking & $41.0 \%$ & $43.5 \%$ & $26.7 \%$ \\
Chi square test of independence & & $\mathrm{p}=0.203$ & $24.6 \%$ \\
\hline Alcohol Consumption & $2.6 \%$ & $20.0 \%$ & \\
Chi square test of independence & & $\mathrm{p}=0.016$ & \\
\hline
\end{tabular}

$>28 \leq 32$ yr: over 28 years and under or equal to 32 years.

Table 6. The correlation between smoking and infertility and between alcohol consumption and infertility in relation to age.

\begin{tabular}{ccc}
\hline & Age $\leq 32$ & Age $>32$ \\
\hline Infertility & \\
\hline Smoking & $\mathrm{r}=-0.057$ & $\mathrm{r}=0.188$ \\
& $\mathrm{p}=0.660$ & $\mathrm{p}=0.150$ \\
\hline Alcohol & $\mathrm{r}=0.343$ & $\mathrm{r}=0.070$ \\
Consumption & $\mathrm{p}=0.008$ & $\mathrm{p}=0.593$ \\
\hline
\end{tabular}

Table 7 shows the results of a discriminant analysis that assesses the effects of alcohol, smoking and age on infertility separately in men with an age $\leq 32$ years and $>32$ years. In men with an age $\leq 32$ years, infertility depends on all the three variables. Alcohol consumption gives a very important contribution to discrimination followed by smoking whereas the contribution from the age is small.

Considering some parameters examined, Table 8 shows the difference between fertility and infertility in relation to the groups of alcohol consumption and smoking. The difference is significant for spermatozoa concentration and atypical spermatozoa in non smokers-non drinkers, it is significant for rectilinear mobility in smokers-non drinkers, and it is significant for rectilinear mobility in drinkers-non smokers. A borderline significance is present for atypical spermatozoa in drinkers non smoking and for spermatozoa concentration, 
Table 7. Discriminant analysis. The effect of alcohol consumption, smoking and age on infertility in relation to the average age.

\begin{tabular}{ccc}
\hline & AGE $\leq 32$ years & AGE $>32$ years \\
\hline Chi square test of independence & $\begin{array}{c}\chi^{2}=8.495 \\
\mathrm{df}=3 \\
\mathrm{p}=0.037\end{array}$ & $\begin{array}{c}\chi^{2}=3.327 \\
\mathrm{df}=3 \\
\mathrm{p}=0.344\end{array}$ \\
\hline Coefficients & & \\
Alcohol & 0.890 & 0.779 \\
Smoking & 0.591 & 0.476 \\
Age & 0.005 & 0.304 \\
\hline
\end{tabular}

Table 8. Some parameters examined: difference between fertile and infertile men in relation to smoking and alcohol consumption.

\begin{tabular}{|c|c|c|c|c|c|c|c|c|c|c|c|c|c|}
\hline & & \multicolumn{3}{|c|}{$\begin{array}{l}\text { No smoking } \\
\text { No alcohol consumption }\end{array}$} & \multicolumn{3}{|c|}{$\begin{array}{l}\text { Yes smoking } \\
\text { No alcohol consumption }\end{array}$} & \multicolumn{3}{|c|}{$\begin{array}{l}\text { Yes alcohol consumption } \\
\text { No smoking }\end{array}$} & \multicolumn{3}{|c|}{$\begin{array}{l}\text { Yes smoking } \\
\text { Yes alcohol consumption }\end{array}$} \\
\hline & & Mean & S.E. & $\mathrm{N}$ & Mean & S.E. & $\mathrm{N}$ & Mean & S.E. & $\mathrm{N}$ & Mean & S.E. & $\mathrm{N}$ \\
\hline \multicolumn{14}{|c|}{ Quantity of Seminal Liquid } \\
\hline Fertility & & 3.64 & 0.35 & 13 & 2.7 & 0.3 & 7 & 4.0 & 0.6 & 3 & - & - & - \\
\hline Infertility & & 2.69 & 0.47 & 10 & 3.7 & 1.2 & 2 & 4.0 & 0.84 & 4 & 5.7 & 1.2 & 2 \\
\hline t-Student & $\mathrm{p}$ & N.S. & & & N.S. & & & N.S. & & & - & & \\
\hline \multicolumn{14}{|c|}{ PH of Seminal Fluid } \\
\hline Fertility & & 7.5 & 0.17 & 4 & 8.2 & 0.15 & 2 & 9 & - & 1 & - & - & - \\
\hline Infertility & & 7.30 & - & 1 & - & - & - & 7.8 & 0.3 & 2 & - & - & - \\
\hline t-Student & $\mathrm{p}$ & - & & & - & & & - & & & - & & \\
\hline \multicolumn{14}{|c|}{ Spermatozoa Concentration } \\
\hline Fertility & & 62.5 & 8.6 & 40 & 51.3 & 10.2 & 17 & 129 & 47.7 & 3 & 94.5 & 51.5 & 2 \\
\hline Infertility & & 32.0 & 6.0 & 27 & 36.0 & 9.3 & 13 & 50.8 & 17.9 & 9 & 14.6 & 6.4 & 5 \\
\hline t-Student & $\mathrm{p}$ & 0.01 & & & N.S. & & & - & & & 0.04 & & \\
\hline \multicolumn{14}{|c|}{ Rectilinear Mobility } \\
\hline Fertility & & 33.3 & 2.6 & 39 & 30.5 & 2.3 & 17 & 25.0 & 5.0 & 3 & 37.5 & 2.5 & 2 \\
\hline Infertility & & 27.8 & 2.7 & 25 & 20.0 & 4.1 & 12 & 30.3 & 6.0 & 7 & 35.1 & 13.8 & 4 \\
\hline t-Student & $\mathrm{p}$ & N.S. & & & 0.02 & & & N.S. & & & 0.03 & & \\
\hline \multicolumn{14}{|c|}{ Spermatozoa Dyskinetic } \\
\hline Fertility & & 11.9 & 1.7 & 27 & 23.7 & 8.4 & 8 & 15.0 & 7.6 & 3 & 7.5 & 2.5 & 2 \\
\hline Infrtility & & 13.9 & 2.6 & 17 & 11.6 & 2.9 & 11 & 10.3 & 2.1 & 7 & 11.5 & 2.5 & 2 \\
\hline t-Student & $\mathrm{p}$ & NS & & & N.S. & & & 0.054 & & & N.S. & & \\
\hline \multicolumn{14}{|c|}{ Atypical Spermatozoa } \\
\hline Fertility & & 66.8 & 2.7 & 40 & 66.6 & 5.3 & 18 & 40.7 & 19.7 & 3 & 90.0 & 3.5 & 4 \\
\hline Infertility & & 79.9 & 2.2 & 25 & 78.8 & 6.8 & 13 & 72.4 & 5.2 & 9 & 71.5 & 4.2 & 3 \\
\hline t-Student & $\mathrm{p}$ & 0.01 & & & N.S. & & & 0.045 & & & 0.03 & & \\
\hline \multicolumn{14}{|c|}{ Varicocele Degree } \\
\hline Fertility & & 2.6 & 0.14 & 37 & 3.0 & 0.2 & 20 & 3 & 0.6 & 3 & 3.0 & 0.0 & 2 \\
\hline Infertility & & 2.9 & 0.14 & 26 & 2.8 & 0.2 & 12 & 2.5 & 0.3 & 8 & 2.7 & 0.3 & 3 \\
\hline t-Student & $\mathrm{p}$ & N.S. & & & N.S. & & & N.S. & & & 0.053 & & \\
\hline
\end{tabular}


rectilinear mobility and atypical spermatozoa the difference is significant in drinkers-smokers but the number of the patients is very small.

Examining the difference between fertility and infertility separately in patients with an age $\leq 32$ years and in those with an age $>32$ years, in patients non smokers-non drinkers we have found a significant difference for spermatozoa concentration $(\mathrm{p}=0.03, \mathrm{n}=33)$ and for atypical spermatozoa $(\mathrm{p}=0.001, \mathrm{n}=31)$, in smokers-drinkers a borderline difference $(\mathrm{p}=0.047, \mathrm{n}=12)$ for atypical spermatozoa and a significant difference $(\mathrm{p}=0.002, \mathrm{n}=10)$ for atypical and diskynetic spermatozoa in drinkers-non smokers.

\section{Discussion}

In the present study we have examined the male partner of couples with marital infertility lasting more than two years. The male partner had varicocele and the mean subject age was 32 years.

As a large number of controversial studies have been made, we focused on the negative effect on sperm parameters of, alcohol consumption and smoking. Our research shows that alcohol is an important risk factor for infertility in men with varicocele. Examining separately the relationship of infertility with smoking and alcohol consumption, only the relationship with alcohol consumption was significant (Table 2). When the relation of infertility with smoking without alcohol consumption and with of alcohol consumption without smoking was assessed, the proportion of alcohol consumers non smokers was higher than the others (Table 3). The correlation analysis between smoking, alcohol consumption and infertility also showed that alcohol consumption is an important risk factor for infertility (Table 4).

The proportion of infertility and alcohol consumption increased significantly with age (Table 5) but alcohol consumption was associated with infertility only in young subjects (Table 6). The absence of this relationship in men older than $32 \mathrm{y}$ is probably due to clinical, environmental or functional factors that remain to be elucidated.

Many clinical studies have demonstrated that alcohol alters and decreases testosterone metabolism. High alcohol consumption and alcohol dependence can cause lower testosterone level and alter sexual function. Testosterone is involved directly in almost all components of the male reproductive process and a decrease in testosterone correlates with a range of clinical problems including reduced fertility, reduced semen volume, impotence and inability to get an erection [1] [16]. Rivier and Vale have also found that alcohol intake stimulates adrenal hormone release which also interferes with reproductive functions in humans and animals [17].

On these men, subsequently, we have examined the association of some genetic polymorphisms with infertility to see their influence on spermatic parameters in particular on spermatozoa motility and male infertility [13] [14] and highlighted that the use of antioxidants supplementation on sperm parameters could 
improve fertility [18]. The sample is small because our study includes only subjects with varicocele. Our results must to be taken into account when they are compared to other studies where the subject group examined includes men with and without varicocele. Despite the limitations our results lay the foundation for broader analyses using larger cohorts and examining populations including individuals with diverse ethnicities and socio-economic background.

\section{Conflicts of Interest}

The authors declare no conflicts of interest regarding the publication of this paper.

\section{References}

[1] Ricci, E., Al Beitawi, S., Cipriani, S., Candiani, M., Chiaffarino, F., Viganò, P., Noli, S. and Parazzini, F. (2017) Semen Quality and Alcohol Intake: A Systematic Review and Meta-Analysis. Reproductive BioMedicine Online, 34, 38-47. https://doi.org/10.1016/j.rbmo.2016.09.012

[2] Mostafa, R.M., Nasrallah, Y.S., Hassan, M.M., Farrag, A.F., Majzoub, A. and Agarwal, A. (2018) The Effect of Cigarette Smoking on Human Seminal Parameters, Sperm Chromatin Structure and Condensation. Andrologia, 50, e12910. https://doi.org/10.1111/and.12910

[3] Boeri, L., Capogrosso, P., Ventimiglia, E., Pederzoli, F., Cazzaniga, W., Chierigo, F., Dehò, F., Montanari, E., Montorsi, F. and Salonia, A. (2019) Heavy Cigarette Smoking and Alcohol Consumption Are Associated with Impaired Sperm Parameters in Primary Infertile Men. Asian Journal of Andrology, 21, 478-485. https://doi.org/10.4103/aja.aja_110_18

[4] Sansone, A., Di Dato, C., de Angelis, C., Menafra, D., Pozza, C., Pivonello, R., Isidori, A. and Gianfrilli, D. (2018) Smoke, Alcohol and Drug Addiction and Male Fertility. Reproductive Biology and Endocrinology, 15, 3. https://doi.org/10.1186/s12958-018-0320-7

[5] Practice Committee of the American Society for Reproductive Medicine (2018) Smoking and Infertility: A Committee Opinion. Fertility and Sterility, 110, 611-618.

[6] Aryanpur, M., Tarahomi, M., Sharif, I.H., Heydari, G., Hessami, Z., Akhoundi, M. and Masjedi, M.R. (2011) Comparison of Spermatozoa Quality in Male Smokers and Nonsmokers of Iranian Infertile Couples. International Journal of Fertility \& Sterility, 5, 152-157.

[7] Gunes, S., Metin Mahmutoglu, A., Arslan, M.A. and Henkel, R. (2018) Smoking-Induced Genetic and Epigenetic Alterations in Infertile Men. Andrologia, 50, e13124. https://doi.org/10.1111/and.13124

[8] Prabhakaran, D.K., Nisha, A. and Varghese, P.J. (2018) Prevalence and Correlates of Sexual Dysfunction in Male Patients with Alcohol Dependence Syndrome: A Cross-Sectional Study. Indian Journal of Psychiatry, 60, 71-77. https://doi.org/10.4103/psychiatry.IndianJPsychiatry_42_17

[9] Xu, W.H., Zhang, X.L., Gao, Y.T., Xiang, Y.B., Gao, L.F., Zheng, W. and Shu, X.O. (2007) Joint Effect of Cigarette Smoking and Alcohol Consumption on Mortality. Preventive Medicine, 45, 313-319. https://doi.org/10.1016/j.ypmed.2007.05.015

[10] Jensen, C.F.S., Østergren, P., Dupree, J.M., Ohl, D.A., Sønksen, J. and Fode, M. (2017) Varicocele and Male Infertility. Nature Reviews Urology, 14, 523-533. https://doi.org/10.1038/nrurol.2017.98 
[11] Jarow, J.P. (2001) Effects of Varicocele on Male Fertility. Human Reproduction Update, 7, 59-64. https://doi.org/10.1093/humupd/7.1.59

[12] Redmon, J.B., Carey, P. and Pryor, J.L. (2002) Varicocele: The Most Common Cause of Male Factor Infertility? Human Reproduction Update, 8, 53-58. https://doi.org/10.1093/humupd/8.1.53

[13] Gentile, V., Nicotra, M., Scaravelli, G., Antonini, G., Ambrosi, S., Saccucci, P., Adanti, S., Bottini, E. and Gloria-Bottini, F. (2014) ACP1 Genetic Polymorphism and Spermatic Parameters in Men with Varicocele. Andrologia, 46, 147-150. https://doi.org/10.1111/and.12059

[14] Gentile, V., Nicotra, M., Minucci, S., Ambrosi, S., Saccucci, P., Gloria-Bottini, F. and Bottini, E. (2015) The Relationship between p53 Codon 72 Genetic polymorphism and Sperm Parameters. A Study of Men with Varicocele. Reproductive Medicine and Biology, 14, 11-15. https://doi.org/10.1007/s12522-014-0188-y

[15] Gentile, V., Nicotra, M., Bottini, E., Gloria-Bottini, F., Modafferi, F. and Gentile, G. (2016) Genetic Variability within ADA Gene Region and Infertility in Subjects with Varicocele. Journal of Andrology \& Gynaecology, 4, 4. https://doi.org/10.13188/2332-3442.1000028

[16] Sarkola, T. and Eriksson, C.J. (2003) Testosterone Increases in Men after a Low Dose of Alcohol. Alcoholism: Clinical and Experimental Research, 27, 682-685. https://doi.org/10.1111/j.1530-0277.2003.tb04405.x

[17] Rivier, C. and Vale, W. (1988) Interaction between Ethanol and Stress on ACTH and $\beta$-Endorphin Secretion. Alcoholism: Clinical and Experimental Research, 12, 206-210. https://doi.org/10.1111/j.1530-0277.1988.tb00181.x

[18] Busetto, G.M., Agarwal, A., Virmani, A., Antonini, G., Ragonesi, G., Del Giudice, F., Micic, S., Gentile, V. and De Berardinis, E. (2018) Effect of Metabolic and Antioxidant Supplementation on Sperm Parameters in Oligo-Astheno-Teratozoospermia, with and without Varicocele: A Double-Blind Placebo-Controlled Study. Andrologia, 50, e12927. https://doi.org/10.1111/and.12927 